\title{
MODERN TRENDS IN THE TREATMENT OF FRACTURED NECK OF FEMUR
}

\author{
By G. P. ARden, M.B., F.R.C.S. \\ Windsor Group Accident Service
}

The treatment of the fractured neck of the femur is a problem which demands our attention to an increasing extent.

Firstly, owing to the ageing population the number of cases is steadily increasing. In the Windsor Group ten years ago we treated 25 cases a year. Last year the number had risen to over 50 , out of a population of 250,000 .

Secondly, although the results have steadily improved, even today about one-third of the cases must be considered a failure.

Astley Cooper (1823) stated, 'In all the examinations (45) which I have made of transverse fractures of the cervix femoris, entirely within the capsular ligament, I have never met with one in which an ossific union had taken place.'

Whitman (1902) began to treat these fractures by manipulation and immobilization in a hip spica; he obtained 24 per cent. union.

Smith Petersen (1936) introduced the tri-fin nail for internal fixation of these fractures after an open reduction. This procedure raised the rate of union to 50 per cent. Johansson (1932) brought in the cannulated trifin nail enabling the operator to introduce the nail on a guide wire using X-ray control. This operation was applicable to a much wider range of elderly patients as the operative shock was minimal.

During the following years a number of papers appeared giving steadily improved results, i.e. Eyre-Brook and Pridie (I94I) claimed 58.7 per cent. Boyd and George claimed 86.5 per cent. union.

The results given by various writers are not

Table I.-Complications Following Fractured Neck of Femur

\begin{tabular}{|c|c|c|c|c|c|}
\hline Year & Author & Treatment & Cases & $\begin{array}{l}\text { Non- } \\
\text { Union }\end{array}$ & $\begin{array}{l}\text { Avascular } \\
\text { Necrosis }\end{array}$ \\
\hline $1930-35$ & Whitman & M.U.A. + hip spica & - & $76.3 \%$ & $77.7 \%$ \\
\hline 1936-37 & Smith-Petersen & Open reduction + S.P. nail & - & $50 \%$ & $42.8 \%$ \\
\hline I937-4I & Eyre-Brook and Pridie & Closed reduction & - & $41.3 \%$ & - \\
\hline 1947 & Boyd and George & Closed reduction + S.P. nail & 122 & $13.5 \%$ & $23.6 \%$ \\
\hline 1948 & Boyd & Closed reduction + S.P. nail & 300 & $13.5 \%$ & $33.6 \%$ \\
\hline 1948 & Patrick & $\begin{array}{l}\text { Closed reduction }+ \text { S.P. nail and fibular } \\
\text { graft }\end{array}$ & 63 & $13 \%$ & $9 \%$ \\
\hline I 948 & Bado & Closed reduction and Moreira lag screw & 45 & $44 \%$ & $22 \%$ \\
\hline $1948-52$ & Cleveland and Fielding & Closed reduction + S.P. nail & ${ }^{63} \mathrm{Av}$ & $\begin{array}{l}22 \% \\
\text { erage age } 7\end{array}$ & $\begin{array}{r}25 \% \\
2 \text { years }\end{array}$ \\
\hline 1956 & Charnley & $\begin{array}{c}\text { Closed reduction }+ \text { compression lag } \\
\text { screw and plate }\end{array}$ & ${ }^{33} \mathrm{O}$ & $\begin{array}{c}18 \% \\
\text { ne year foll }\end{array}$ & ow-up \\
\hline \multirow[t]{2}{*}{1957} & Arden & Closed reduction + S.P. nail & $\begin{array}{r}{ }^{34} \mathrm{~T} \\
\mathrm{Av}\end{array}$ & $\begin{array}{c}18 \% \\
\text { wo year foll } \\
\text { erage age } 7\end{array}$ & $\begin{array}{r}24 \% \\
\text { ow-up } \\
6 \text { years }\end{array}$ \\
\hline & & Average & & $\mathbf{2 2 . 9} \%$ & $22.8 \%$ \\
\hline
\end{tabular}




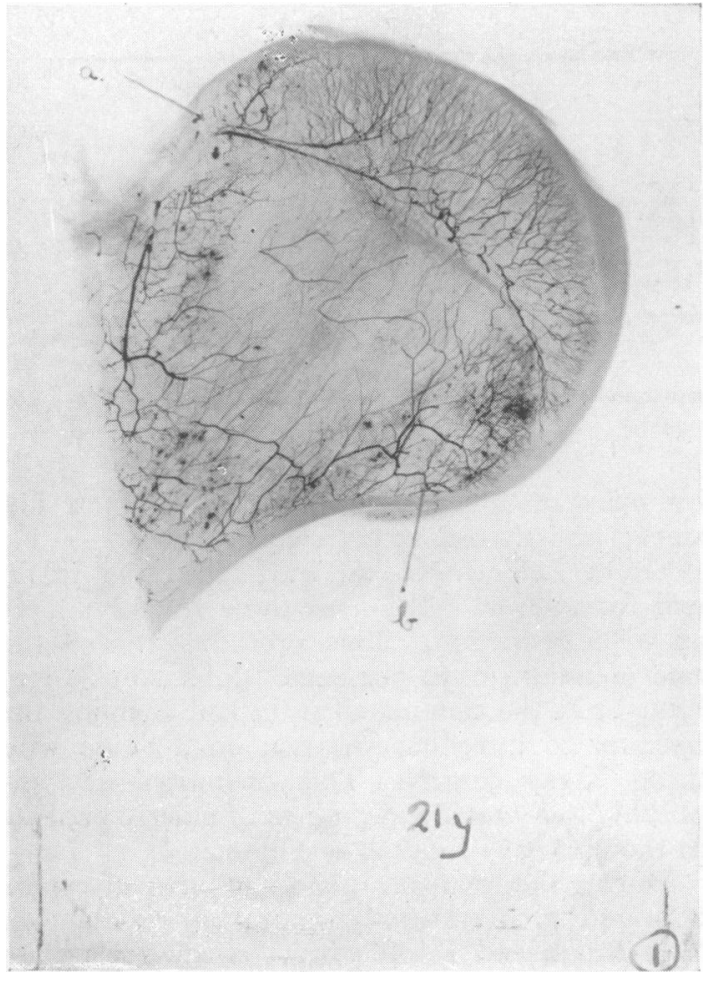

Fig. I.-X-ray of a femoral head from a patient aged 2 I years following barium injection of vessels:

(a) Superior epiphyseal artery.

(b) Inferior metaphyseal artery.

always comparable for the following reasons. Firstly, the average age of the patients treated has steadily risen and with it the co-existence of other medical disabilities (hemiplegia, coronary disease, hypertension, cerebral changes, Parkinsonism, etc.). Secondly, the cases of today are less selected in that almost all cases with this fracture are fit for operative treatment. Thirdly, some authors have operated on cases of impacted fractures of the neck of the femur ( 8 per cent.) which in themselves carry a far better prognosis with regard to union, whether nailed or not.

Fourthly, the follow-up period in different series has varied. A minimum of two years is now regarded as essential, and it is probable that this should be extended to five years since avascular necrosis has occurred as late as four and a half years after a fracture of the neck of the femur, in this series.

From table I it will be seen that there is a considerable variation in results probably for the reasons given above, but the average is 23 per cent. non-union and 23 per cent. avascular necrosis-

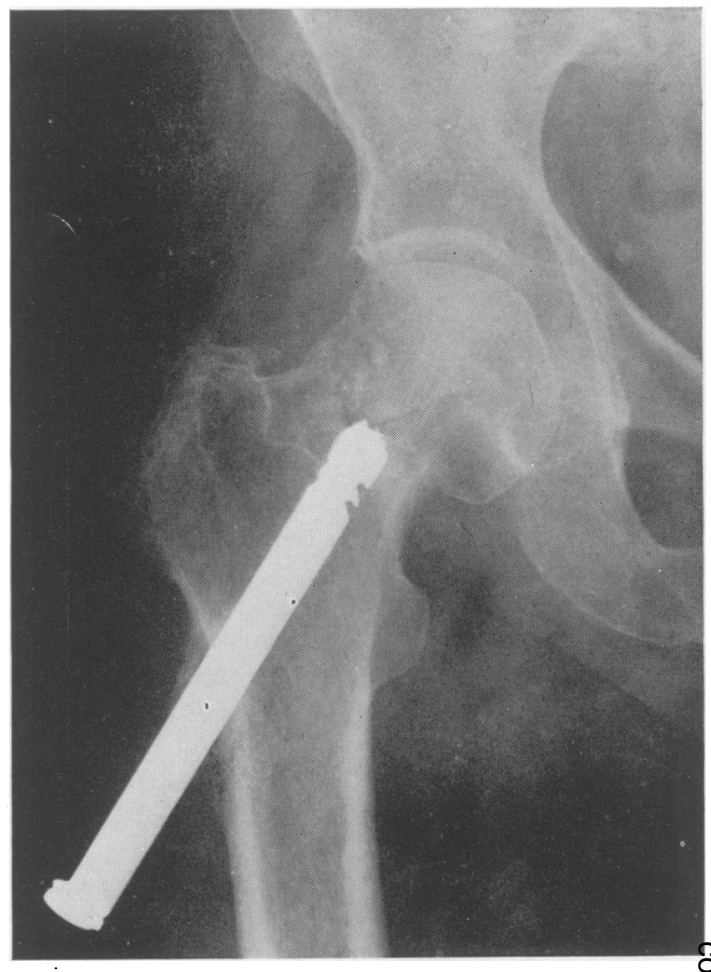

FIG. 2.-X-ray showing Group I fracture of neck of. femur passing flush with the head above, damagin the superior epiphyseal artery.

between them giving rise to approximately 33 per cent. of unsatisfactory results.

\section{Causes of $33 \%$ Poor Results}

I. Non-union.

2. Avascular necrosis due to:

(a) Difficulty of fixation.

(b) Age and debility of patient.

(c) Blood supply.

One must now consider the special problems appertaining to this fracture. It will be apparent that the lower fragment is a long bony lever subject to rotation and other strains, whereas the upper fragment (head of femur) is small, mobile and inaccessible, hence it is difficult to apply the first principle of fracture treatment-i.e. immobilization.

Pauwels has shown that the more vertical the fracture the worse the prognosis. He claimed that this was due to the vertical shearing force preventing union (Pauwel's angle over $50^{\circ}$ ). Those cases with less than $50^{\circ}$ and hence a more transverse fracture line did better. However, it will be seen later that damage to the blood supply may also explain this fact. 


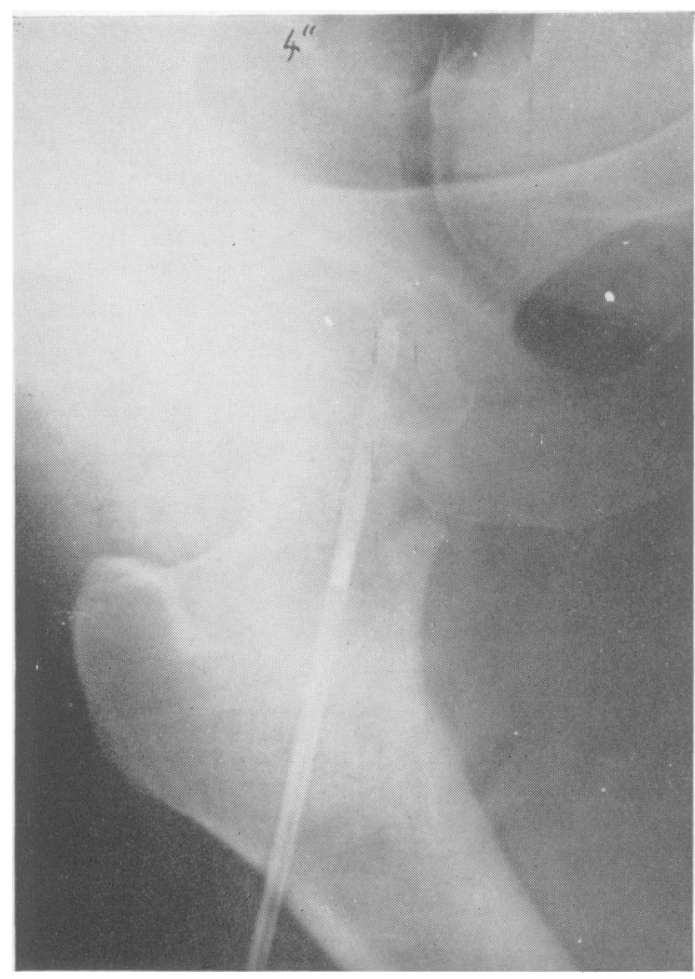

FIG. 3.-X-ray showing needle counter in head of femur.

It has already been mentioned that most of these patients are old and belong to the 60 to 80 years age group. While this is probably not a factor in producing non-union or avascular necrosis it does raise the mortality of any operative procedure. (This has dropped from 30 per cent. to 10 per cent. in the last 20 years.) Age also seriously interferes with the rehabilitation of the convalescent patient.

The third factor concerning this fracture, and probably the most important, is the arrangement of the blood vessels in the region of the hip joint. Recent work strongly suggests that while nonunion may in part be due to poor reduction and poor immobilization, damage to the blood supply may be the main factor, and avascular necrosis is very largely due to a damaged blood supply.

Blood Supply to the Head of Femur

I. Postero-superior .. Branches of medial femoral circumflex.

2. Postero-inferior .. Branches of medial femoral 3. Antero-lateral .. Branch of lateral femoral circumflex.

4. Foveolar .. . . Branch of obturator.

Tucker (1949) described the blood supply to the hip joint as shown. He drew attention to the

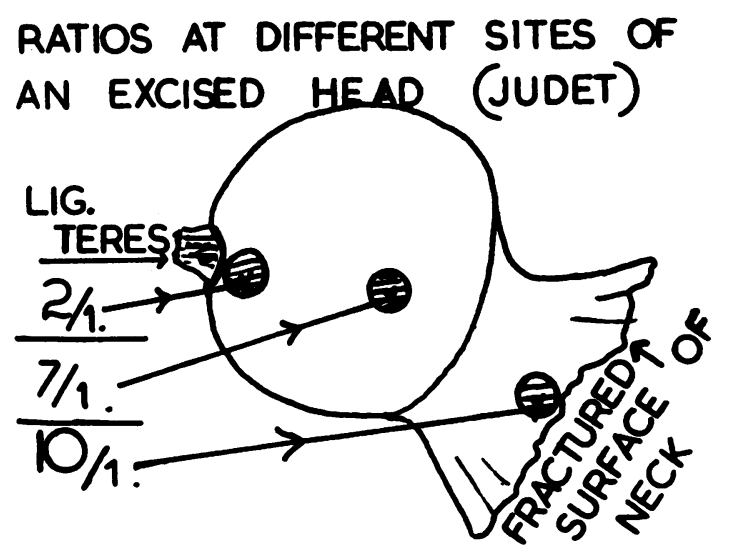

FIG. 4.-Diagram showing varying ratios in an excised head of femur, $P_{32}$ having been given one hour previously.

fact that the postero-superior vessels in the superior retinaculum were fairly mobile. He found that the foveolar vessels supplied the head of the femur in only about one-third of children and in about two-thirds of adults, slowly increasing with age.

Trueta and Harrison (1953), working at Oxford, published a detailed description of the arrangements of vessels to the femoral head as shown by barium injection of the vessels in post-mortem heads of femora and then X-raying the specimens.

They found that the superior epiphyseal artery (postero-superior) supplied two-thirds of the head of the femur and that it had an extra-osseous course in the superior retinaculum and an intraosseous course after leaving the neck, and on entering the head. They pointed out that in cases of fractured neck of femur with displacement this important vessel was very liable to injury.

In 1955, the Judet brothers repeated this work and largely confirmed the above findings. They found that the blood supply did not change with the age and that the same pattern prevailed.

Trueta and Claffey analysed the line of the fracture in fractured neck of the femur. Those cases in which the fracture line passed flush with the head superiorly but went through a portion of neck inferiorly were Group I and the rest Group II.

They found that Group I ( 13 per cent.) all had a poor prognosis and they suggested that this was because the intra-osseous course of the superior epiphyseal was torn. This Group I is the same as those with an unfavourable Pauwel's angle (over $\left.50^{\circ}\right)$.

Hulth has investigated the blood supply of the head of the femur by venography: 5 c.c. of 50 per cent. Diodone was injected into the centre of the femoral head along a cannula. In 50 per cent. filling of the veins occurred and were visible on 


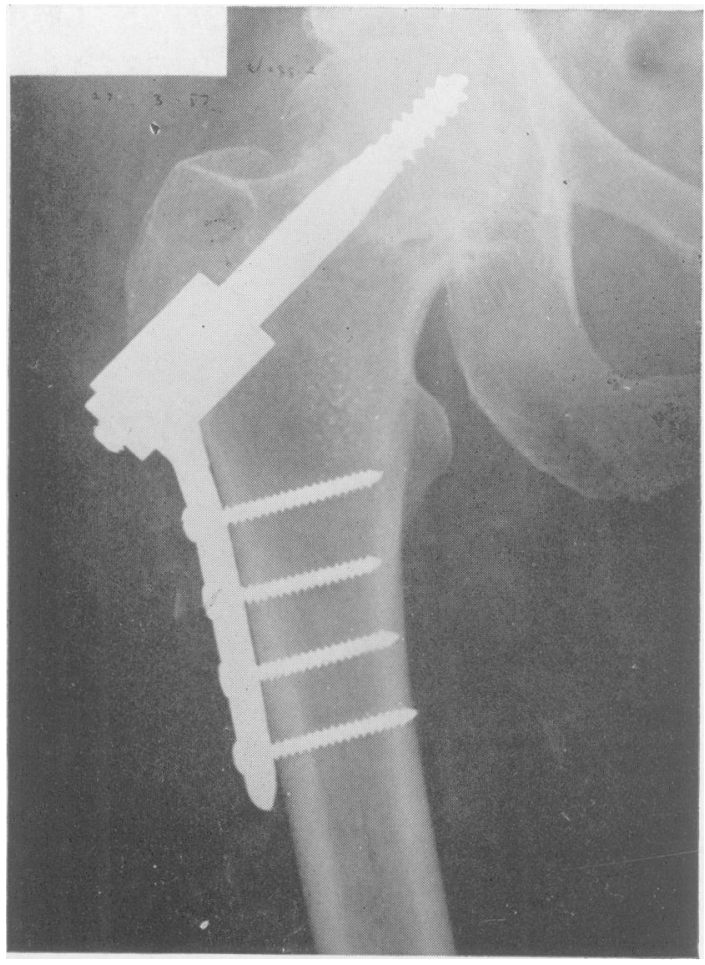

FIG. 5.-Charnley spring loaded compression lag screw with plate holding fracture of neck of femur in position.

$\mathrm{X}$-ray; these veins are parallel to the arteries. All negative venographies developed avascular manifestations to a greater or lesser degree within a year. If negative Hulth advised a delay in weight bearing. Those cases with good positive venographs did well.

\section{Isotope Studies}

Tucker (1949) investigated the blood supply to the head of the femur, first in dogs and later in man. He injected radio-active phosphorus ( $\left.P_{32}\right)$ in an intravenous solution of $\mathrm{Na}$ phosphate, and one hour later removed samples of bone from the head and trochanter of the femur. The samples were assayed and the results expressed as a ratio Trochanter/Head. In normal dogs and in intertrochanteric fractures in man (no damage to the blood supply) the ratios were found to be $\mathrm{I} / \mathrm{I}$ or $2 / 1$. In cases of fractured neck of the femur he found that the ratio sometimes varied widely.

I have myself repeated this work and published the results of a small series of 16 cases using the bone sampling technique. I also carried out this procedure on six intertrochanteric fractures as a control and confirmed Tucker's results in that these cases had a normal ratio range.

\begin{tabular}{|c|c|}
\hline & \\
\hline ntert & acture \\
\hline $\begin{array}{l}1.7 / 1 \\
1.5 / 1\end{array}$ & $\begin{array}{l}2.5 / . \\
\mathrm{I} / 2\end{array}$ \\
\hline $\begin{array}{l}1.5 / 1 \\
1.5 / 1\end{array}$ & \\
\hline
\end{tabular}

All the fractures united except one patient who died.

Boyd (I955) carried this work one stage further by taking direct readings in the head and trochanter of the femur using a needle counter at the time of the nailing operation.

I have also been using this technique for the last three years.

It will be seen from table 2 that on the average there is a serious disturbance to the blood supply in 23.5 per cent.

The reason for the varying results is probably because the needle counter is put into different portions of the head in which the deposition of $\mathrm{P} 32$ will vary.

\section{Method of Fixation}

Since Smith-Petersen (I95I) introduced his trifin nail, various surgeons have tried to improve on this as a method of fixation. Moore (1934) used multiple pins. Lippman (1937) described a lag screw fixation and Moreira (1937) improved on this. Putti emphasized the importance of 
impaction of the fracture at operation. Patrick (I949) claimed excellent results with a combined Smith-Petersen nail and a fibular graft. Tobin (1955) supported the low trifin nail resting on the calcar as the ideal mechanical support for this fracture. Charnley (1956) described a spring loaded compression lag screw with shaft fixation designed to combine all the advantages of the previous methods.

In 33 patients with a one-year follow-up he obtained 82 per cent. union.

Technical Faults of Reduction AND Smith-Petersen NaIling

I. Poor reduction.

2. Poor nailing:
(a) Nail too short or too long.
(b) Rotation of head.
(c) Extrusion or migration of nail.
(d) Nail cutting out.
(e) Metal failure or reaction.

A poor reduction is a common fault and makes the whole operation more difficult besides giving the patient little chance of the fracture uniting. Disimpaction of the fracture, rotation or penetration of the head are avoided by the Charnley apparatus. Cutting out of the nail is often due to the nail being too anterior, but sometimes is due to a dead head.

Charnley reports three cases of this complication with his new lag screw. Extrusion of the nail is not uncommon. It may be prevented by a plate but then there is a danger of the nail penetrating the head as the neck absorbs at the fracture site. One of the great advantages of the Charnley apparatus is that the spring takes up the absorption of the neck and this can be measured in X-rays. The greater the take-up, the worse the prognosis.

Metal failure is becoming less common with better standardization of stainless steels and with a gradual change to vitallium. Charnley reports one case of metal failure with his spring loaded lag screw.

Both in this country and on the Continent there is now a swing away from the Smith-Petersen cannulated trifin nail for fixation of these fractures. This nail has been widely used for 25 years but it now appears that a better method of fixation will replace it.

Vascular and isotope studies indicate that in about 25 per cent. of fractures of the neck of the femur the blood supply is badly damaged and therefore 75 per cent. success is probably the best that can be hoped for if all technical faults can be eliminated. Lesser degrees of damage to the blood supply may give rise to avascular necrosis at a later stage. Delayed weight bearing until three months or longer from the date of the fracture may help to reduce permanent damage from this cause.

\section{Summary}

Improved techniques have brought about a remarkable change in the results of fractures of the neck of the femur during the last 80 years: from Ioo per cent. non-union in the days of Astley Cooper to 23 per cent. non-union today.

The most important factors in treatment would appear to be:

I. Early and gentle reduction to avoid damage to the blood supply.

2. Accurate reduction.

3. Good fixation-Charnley type.

4. Better metals.

5. Delayed weight bearing until at least three months.

\section{Acknowledgment}

I am grateful to Professor J. Trueta for Fig. I and to Mr. N. Veall, B.Sc., for his help and advice with the isotope studies.

\section{BIBLIOGRAPHY}

ARDEN, G. P., and VEALL, N. (r950), Proceeding R.S.M.

ASTLEY COOPER, SIR (1823), ' Observations on the fracture of the neck of the thigh bone,' Quarto Tracts.

BADO, J. L. (I948), Ibid., 30a, 295-302.

BOYD, H. B., ZILVERMIT, D. B., and COLANDRUCCIO, R. A. (1955), Ibid., 37a, 260.

BOYD, H. B., and GEORGE, I. L. (1948), f. Amer. med. Ass., 137, I I $196-1199$.

CHARNLEY, J., BLOCKEY, N. J., and PURSER, D. W. (1957), Ұ. Bone $\mathscr{f} t$ Surg., 39, 45.

CLEVELAND, M., and BAILEY, W. L. (1950), Surg. Gynec. Obstet., 90, 393-405.

CLEVELAND, M., and FIELDING, J. W. (1954), Ibid., 36a, IO20.

EYRE-BROOK, A. L., and PRIDIE, K. H. (I94I), Ibid., 29, II 5-I 38 .

GODOY-MOREIRA, E. F. (1940), Ibid., 22, 683.

HULTH, A. (1956), Acta. chir. scand., Supplementum 214, Stockholm.

JOHANSON, SVEN (1932), Acta orthop. scand., 3, 362-392.

JUDET, J., JUDET, R., LAGRANGE, J., and DUNOYER, J. (1955), Ibid., 37a, 663.

LIPPMAN, R. K. (1940), f. Bone ft Surg., 21, 735.

PATRICK, J. (r949), Ibid., 3ra, 67.

PAUWELS, F. (1935), ' Prognose und Kansale Therapie,' Stuttgart, Ferdinand Enke.

SMITH-PETERSEN, M. N., CAVE, E. F., and VAN GORDER, G. W. (195I), Arch. Surg. (Chicago), 23, 71 5-759.

TRUETA, J.; and CLAFFEY (1957), Lecture, ' Nuffield Institute of Orthopaedics.'

TRUETA, J., and HARRISON, M. H. M. (1953), f. Bone $f t$ Surg., $35 \mathrm{~b}, 442-46 \mathrm{r}$.

TUCKER, F. R. (1949), F. Bone ft Surg., 31b, 82-93.

WHITMAN, R. (1902), Ann. Surg. 36, 746-761. 